\title{
The Utility of PET/CT in the Planning of External Radiation Therapy for Prostate Cancer
}

\author{
Jeremie Calais ${ }^{1}$, Minsong $\mathrm{Cao}^{2}$, and Nicholas G. Nickols ${ }^{2,3}$ \\ ${ }^{1}$ Ahmanson Translational Imaging Division, Department of Molecular and Medical Pharmacology, UCLA, Los Angeles, California; \\ ${ }^{2}$ Department of Radiation Oncology, UCLA, Los Angeles, California; and ${ }^{3}$ Department of Radiation Oncology, VA Greater Los \\ Angeles Healthcare System, Los Angeles, California
}

\begin{abstract}
Learning Objectives: On successful completion of this activity, participants should be able to (1) understand the basic principles of prostate cancer radiotherapy planning, (2) give a brief overview of different PET/CT molecular imaging probes for prostate cancer and their applications for prostate cancer radiotherapy planning, and (3) provide an up-to-date review of the relevant recent and ongoing retrospective and prospective studies on the impact of PET/CT molecular imaging for prostate cancer radiotherapy planning.

Financial Disclosure: Jeremie Calais is the recipient of a grant from the Foundation ARC pour la recherche sur le cancer (grant SAE20160604150). Nicholas Nickols is a Prostate Cancer Foundation Young Investigator and a recipient of a VA Career Development Award (5IK2BX002520), a UCLA Prostate SPORE Career Enhancement Award (4P50CA092131), a STOP Cancer Foundation Career Development Award, and a UCLA JCCC Seed Grant. The authors of this article have indicated no other relevant relationships that could be perceived as a real or apparent conflict of interest.

CME Credit: SNMMI is accredited by the Accreditation Council for Continuing Medical Education (ACCME) to sponsor continuing education for physicians. SNMMI designates each JNM continuing education article for a maximum of 2.0 AMA PRA category 1 credits. Physicians should claim only credit commensurate with the extent of their participation in the activity. For CE credit, SAM, and other credit types, participants can access this activity through the SNMMI website (http://www.snmmilearningcenter.org) through April 2021.
\end{abstract}

Radiotherapy and radical prostatectomy are the definitive treatment options for patients with localized prostate cancer. A rising level of prostate-specific antigen after radical prostatectomy indicates prostate cancer recurrence, and these patients may still be cured with salvage radiotherapy. To maximize chance for cure, the irradiated volumes should completely encompass the extent of disease. Therefore, accurate estimation of the location of disease is critical for radiotherapy planning in both the definitive and the salvage settings. Current firstline imaging for prostate cancer has limited sensitivity for detection of disease both at initial staging and at biochemical recurrence. Integration of PET into routine evaluation of prostate cancer patients may improve both staging accuracy and radiotherapy planning. ${ }^{18} \mathrm{~F}-\mathrm{FDG}$ $\mathrm{PET} / \mathrm{CT}$ is now routinely used in radiation planning for several cancer types. However, ${ }^{18}$ F-FDG PET/CT has low sensitivity for prostate cancer. Additional PET probes evaluated in prostate cancer include ${ }^{18} \mathrm{~F}$-sodium fluoride, ${ }^{11} \mathrm{C}$-acetate, ${ }^{11} \mathrm{C}$ - or ${ }^{18} \mathrm{~F}$-choline, ${ }^{18} \mathrm{~F}$-fluciclovine, and ${ }^{68} \mathrm{Ga}$ - or ${ }^{18} \mathrm{~F}$-labeled ligands that bind prostate-specific membrane antigen (PSMA). PSMA ligands appear to be the most sensitive and specific but have not yet received Food and Drug Administration New Drug Application approval for use in the United States. Retrospective and prospective investigations suggest a potential major impact of PET/CT on prostate radiation treatment planning. Prospective trials randomizing patients to routine radiotherapy planning versus $\mathrm{PET} / \mathrm{CT}$-aided planning may show meaningful clinical outcomes. Prospective clinical trials evaluating the addition of ${ }^{18} \mathrm{~F}$-fluciclovine PET/ CT for planning of salvage radiotherapy with clinical endpoints are under way. Prospective trials evaluating the clinical impact of PSMA $\mathrm{PET} / \mathrm{CT}$ on prostate radiation planning are indicated.

Received Oct. 2, 2017; revision accepted Dec. 1, 2017

For correspondence or reprints contact: Nicholas G. Nickols, UCLA, 10833

Le Conte Ave., Room 23-120 CHS, Los Angeles, CA 90095.

E-mail: nnickols@mednet.ucla.edu

Guest Editor: David Mankoff, University of Pennsylvania.

Published online Jan. 4, 2018.

COPYRIGHT (c) 2018 by the Society of Nuclear Medicine and Molecular Imaging.
Key Words: prostate cancer; PSMA; PET/CT; radiation

J Nucl Med 2018; 59:557-567

DOI: 10.2967/jnumed.117.196444

$\mathbf{P}$ rostate cancer was expected to have an incidence of 161,000 and mortality of 27,000 in the United States during 2017 (1). Curative treatments for localized prostate cancer include radical prostatectomy or radiotherapy (2). Locally recurrent disease after radical prostatectomy may be cured by salvage radiotherapy (SRT) (3). The effectiveness of any local therapy depends on accurate imaging to rule out areas of disease that would remain untreated. ${ }^{99 \mathrm{~m}} \mathrm{Tc}$ bone scans and CT or MRI of the abdomen and pelvis are used to evaluate osseous metastases and evaluate soft-tissue and nodal metastases, respectively, for prostate cancer staging. For initial staging, ${ }^{99 \mathrm{~m}} \mathrm{Tc}$ bone scans have sensitivities and specificities for osseous metastases of $46 \%-89 \%$ and $32 \%-57 \%$, respectively $(4,5)$. CT and MRI both have sensitivities and specificities for nodal metastases of $39 \%-42 \%$ and $82 \%(6)$. The accuracy of these scans is low, commonly resulting in underestimation of disease burden. After failure of local therapy, recurrence is detected by a rising level of prostate-specific antigen (PSA). However, the sensitivity of current first-line imaging is too low to visualize recurrence in time to guide salvage treatment (7-9).

Intuitively, irradiated volumes should completely encompass the extent of disease. Therefore, accurate estimation of the location of disease is critical during the process of radiotherapy planning. Radiation oncologists make a distinction in treatment volumes that include gross disease seen on imaging (the gross target volume) and volumes that do not include radiographic visible disease but are at high risk of harboring disease (the clinical target volume, or CTV). Gross disease is prescribed a higher dose if feasible (taking into account risks to adjacent normal tissue) to increase the probability of tumor control and ultimately cure. PET/CT might improve staging accuracy and affect radiotherapy planning for prostate cancer. 
Integration of PET/CT during radiotherapy planning is routine in many cancer types $(10) .{ }^{18} \mathrm{~F}-\mathrm{FDG}$, which detects increased glucose metabolism within malignant tumors $(11-13)$, assists radiation planning for cancers of the head and neck $(14)$, lung $(15,16)$, gastrointestinal tract (10), and cervix (17), as well as for lymphoma $(18,19)$. ${ }^{18}$ F-FDG PET/CT, however, has a low sensitivity for detection of prostate cancer, severely limiting its use $(20,21)$, with the possible exception of aggressive poorly differentiated and small cell prostate cancers $(20,22)$, which constitute a small fraction of prostate cancers treated with radiotherapy.

Other PET probes have been evaluated in prostate cancer patients (21). These tracers can target either the metabolic changes characteristic of prostate cancer cells (phospholipids with ${ }^{11} \mathrm{C}$ - or ${ }^{18} \mathrm{~F}$-choline, fatty acids with ${ }^{11} \mathrm{C}$-acetate, amino acids with ${ }^{18} \mathrm{~F}$ fluciclovine), bone remodeling from osteoblastic osseous metastases ( ${ }^{18} \mathrm{~F}$-sodium fluoride), or overexpressed cell surface proteins (labeled ligands to prostate-specific membrane antigen, PSMA) (21). ${ }^{11} \mathrm{C}$-choline and ${ }^{18} \mathrm{~F}$-fluciclovine (anti-1-amino-3-3 ${ }^{18} \mathrm{~F}$-fluorocyclobutane-1-carboxylic acid [Axumin; Blue Earth Diagnostics, Inc.]) have Food and Drug Administration New Drug Application approval in the United States for imaging of recurrent prostate cancer after local therapy (23). The PSMA ligands appear to be the most sensitive and specific for detection of local and metastatic disease (24-26) but are not yet approved for use.

We review the available scientific literature with 3 goals: to describe how PET/CT imaging may affect prostate radiotherapy planning, to assess the potential impact of various PET/CT imaging strategies on the planning process, and to describe current investigations aimed at measuring this impact.

\section{SUMMARY OF PET PROBES}

${ }^{18} \mathrm{~F}$-sodium fluoride PET/CT localizes preferentially to areas of active bone remodeling, which is characteristic of osteoblastic prostate cancer bone metastases. Advantages over planar ${ }^{99 \mathrm{~m}} \mathrm{Tc}$ bone imaging include a higher signal-to-noise ratio and less time needed between injection and imaging (27). Some reports suggest improved sensitivity and specificity for ${ }^{18} \mathrm{~F}$-sodium fluoride PET/ CT as compared with planar bone scans $(5,28,29) .{ }^{18} \mathrm{~F}$-sodium fluoride PET/CT is approved, but its clinical use has been limited because it is not widely reimbursed. It does not image soft-tissue or nodal disease.

${ }^{11} \mathrm{C}$ - and ${ }^{18} \mathrm{~F}$-choline probes offer selectivity to prostate cancer tissue because of increased choline transport, which might be due to changes in cell membrane synthesis and proliferation (21). ${ }^{11} \mathrm{C}$-choline PET/CT can detect evidence of recurrent disease in $80 \%$ of patients with biochemical recurrence after prostatectomy at a PSA level of $2 \mathrm{ng} / \mathrm{mL}$, greatly exceeding that of current first-line imaging. As a result, ${ }^{11} \mathrm{C}$-choline was Food and Drug Administrationapproved in 2012 in the United States for imaging of recurrent prostate cancer after local failure (30).

Anti-1-amino-3- ${ }^{18} \mathrm{~F}$-fluorocyclobutane-1-carboxylic acid $\left({ }^{18} \mathrm{~F}-\right.$ fluciclovine), a synthetic amino acid analog, is taken up by cells through the amino acid transporters ASCT2 and LAT-1 $(31,32)$. Like ${ }^{11} \mathrm{C}$ - and ${ }^{18} \mathrm{~F}$-choline tracers, the specificity of ${ }^{18} \mathrm{~F}$-fluciclovine for prostate cancer relies on altered metabolic pathways. ${ }^{18}$ F-fluciclovine PET/CT has been evaluated extensively in the setting of biochemical recurrence. A recent large, multisite study reported a detection rate of $40 \%$ for patients with biochemical recurrence and a PSA level of $0.79 \mathrm{ng} / \mathrm{mL}$ or less (33). Improved detection rates of recurrent prostate cancer using ${ }^{18} \mathrm{~F}$-fluciclovine as compared with ${ }^{11} \mathrm{C}$-choline led to the approval of ${ }^{18} \mathrm{~F}$-fluciclovine for imaging of recurrent prostate cancer in $2016(23,34)$. Evaluations of ${ }^{18} \mathrm{~F}$-fluciclovine in the initial staging of prostate cancer are ongoing (NCT03081884).

PSMA is a cell surface glycoprotein and folate hydrolase highly expressed on prostate cancer cells (35). Expression increases with Gleason score $(36,37)$ and remains high during the castrationresistant disease state (38). The best-studied PSMA probes are small-molecule ligands, such as ${ }^{68} \mathrm{Ga}-\mathrm{PSMA}-11$ and 2-(3-(1carboxy-5-[(6- ${ }^{18}$ F-fluoro-pyridine-3-carbonyl)-amino]-pentyl)-ureido)pentanedioic acid $\left({ }^{18} \mathrm{~F}-\mathrm{DCFPyL}\right)$, that bind the enzymatic active site. A recent report of 120 intermediate- and high-risk patients who underwent ${ }^{68} \mathrm{Ga}$-PSMA PET/CT for initial staging followed by radical prostatectomy showed a sensitivity of $66 \%$ and specificity of $98.9 \%$ for lymph node metastases detected by ${ }^{68} \mathrm{Ga}$-PSMA PET/CT (39). However, a smaller study (40) reported a lower sensitivity. Ongoing studies will be required for clarification. ${ }^{68} \mathrm{Ga}$-PSMA PET/CT also outperformed planar bone scans for detection of osseous metastases in large retrospective analyses $(41,42) .{ }^{68} \mathrm{Ga}$-PSMA PET/CT, like ${ }^{11} \mathrm{C}$-choline and ${ }^{18} \mathrm{~F}$-fluciclovine, has been studied most in patients with recurrent prostate cancer after failure of local therapy. Large retrospective series reveal detection rates from $50 \%$ to $58 \%$ for patients with a PSA level of less than $0.5 \mathrm{ng} / \mathrm{mL}$, and more than $95 \%$ when the PSA level is more than $2 \mathrm{ng} / \mathrm{mL}(25,43)$. The detection rate of ${ }^{68} \mathrm{Ga}$-PSMA PET/CT for recurrent prostate cancer exceeds that of ${ }^{18} \mathrm{~F}$ - and ${ }^{11} \mathrm{C}$-choline PET/CT $(44,45)$ and may exceed ${ }^{18}$ F-fluciclovine PET/CT (24). No PSMA PET probes have Food and Drug Administration New Drug Application approval for use in the United States, but numerous trials are under way (NCT02918357, NCT02919111, NCT02673151, NCT02940262). The high and largely specific expression of PSMA exclusive to prostate cancer cells led to development of PSMA-targeted radioligand therapeutics (46). ${ }^{177} \mathrm{Lu}$-PSMA has demonstrated efficacy in patients with treatmentrefractory metastatic castration-resistant prostate cancer $(46,47)$. Larger trials are under way (NCT03042312).

The remainder of this review will focus on the use of ${ }^{18} \mathrm{~F}$ - and ${ }^{11} \mathrm{C}$-choline, ${ }^{18} \mathrm{~F}$-fluciclovine, and PSMA PET/CT imaging for planning definitive radiotherapy and SRT.

\section{PROSTATE RADIOTHERAPY PLANNING}

Before planning, the radiation oncologist first delineates the gross target volume and areas suspected of being occult tumor (CTV). A final volume (the planning tumor volume) takes into account daily patient set-up errors and is typically an isometric expansion of the CTV. Organs at risk (e.g., bladder, rectum) are also delineated. The aim of the radiation oncologist is to deliver the highest possible dose to the tumor without impairing function of surrounding organs. Modern treatment planning leverages advances in patient positioning and immobilization systems, dynamic multileaf collimators, inverse planning techniques, and computerized delivery. The end result is highly conformal, reproducible delivery of dose to target volumes (CTVs and planning tumor volumes), with adequate sparing of adjacent normal tissues and organs (specifically, organs at risk). Therefore, the accurate delineation of the malignant tissue itself is a critical limiting factor for improving the efficacy of modern radiotherapy. Treatment planning is most often based on CT because electron densities, which are required for accurate dose calculations, can be inferred from Hounsfield units. To aid target delineation, other imaging modalities such as MRI and PET/CT can be fused to the dedicated planning CT scan through mutual-information-based 


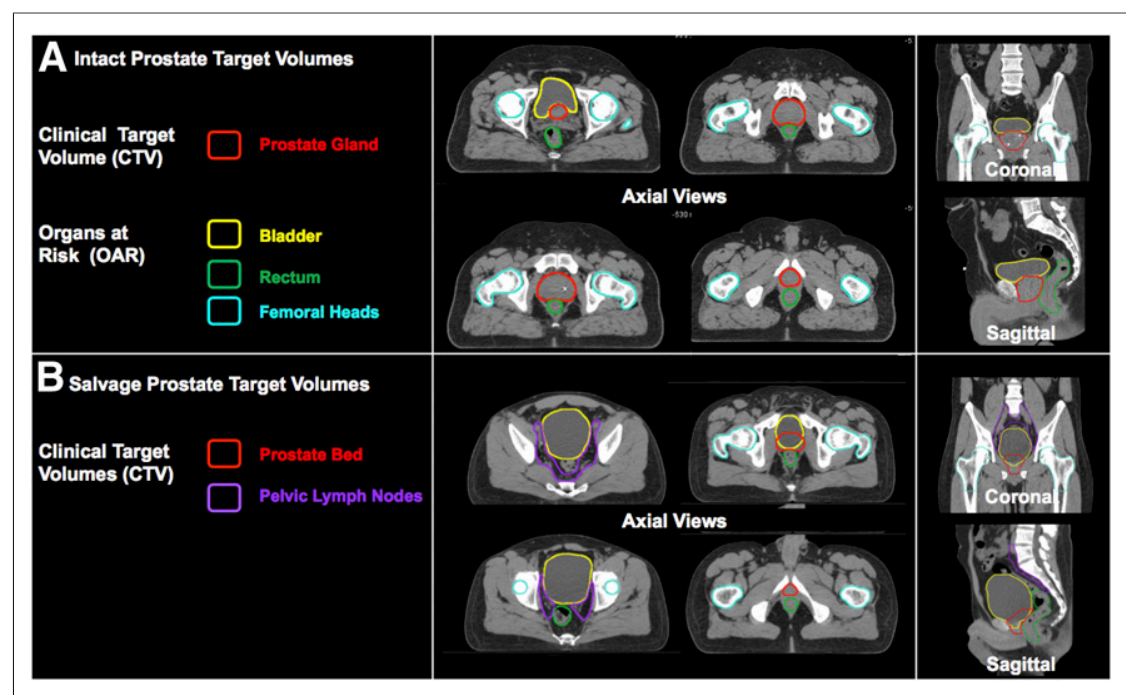

FIGURE 1. CTV contours and organs at risk are contoured by radiation oncologists on dedicated planning CT (CT simulation). (A) CTV for intact (definitive) prostate is prostate gland itself with or without pelvic nodes and seminal vesicles. (B) CTV for SRT includes prostate bed with or without pelvic nodes. CTV is usually drawn in absence of radiographic evidence of recurrent disease. Instead, CTVs are based on consensus guidelines to encompass prostate bed with or without pelvic lymph nodes. The most commonly used external-beam dose-fractionation schedules for definitive prostate radiotherapy deliver 75.6-79.2 Gy in fractions of 1.8-2 Gy, whereas those for SRT deliver 66-72 Gy. When included, pelvic nodal volumes are prescribed 45-50.4 Gy.

image registration. The planning target can be defined on the basis of these images, and the resultant target contours can be transferred back to the dedicated planning CT for treatment planning (Figs. 1 and 2).
Radiotherapy is a potentially curative therapy for localized prostate cancer alone or in combination with hormonal therapy, and a potentially curative SRT for recurrent prostate cancer after radical prostatectomy. Notably, gross prostate tumor is often not visible on CT. MRI can reveal intraprostatic tumor foci with good sensitivity (48), but most prostate tumors are multifocal, with some occult lesions unseen on MRI (49). Therefore, in the definitive setting, the CTV includes the entirety of the prostate, with or without inclusion of the seminal vesicles and pelvic lymph nodes, depending on clinicopathologic features. Figure 1A shows the CTV and organs at risk delineated for a typical low to favorable intermediate-risk prostate cancer patient. The prostate is prescribed a higher dose than the nodes (if included). In the salvage setting, the CTV is the prostate fossa and seminal vesicle remnants, with or without inclusion of the pelvic lymph nodes. Figure 1B shows the CTVs and organs at risk for a patient with recurrent prostate cancer to undergo SRT, with elective pelvic nodal coverage included. SRT target volumes are usually drawn in the absence of radiographic evidence of recurrent disease. In practice, most physicians base their CTVs on published consensus guidelines. The Radiation Therapy Oncology Group (RTOG) has published guidelines for

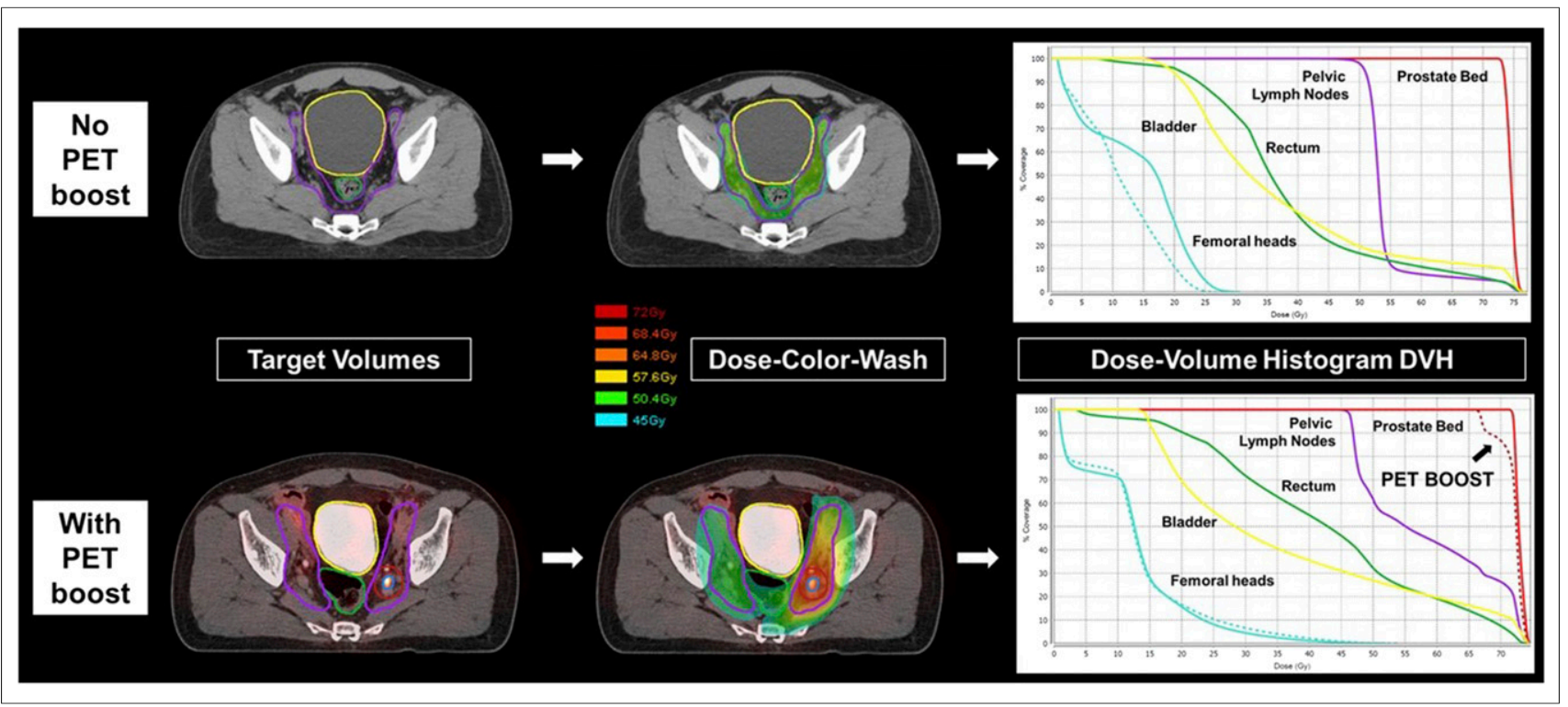

FIGURE 2. ${ }^{68} \mathrm{Ga}-\mathrm{PSMA}$ PET enables identification of areas of gross disease that are missed on CT. Intensity-modulated radiotherapy can be used to deliver higher dose to areas with gross disease. At top is example of SRT plan and dose-volume histogram for patient with rising PSA level after radical prostatectomy planned without radiographic evidence of visible gross disease. Pelvic nodal and prostate bed volumes are prescribed doses of 45 and $72 \mathrm{~Gy}$, respectively. At bottom is example of SRT plan and dose-volume histogram for patient who underwent ${ }^{8} \mathrm{Ga}-\mathrm{PSMA} \mathrm{PET}$ before planning. ${ }^{68 \mathrm{Ga}-}$ PSMA PET enabled identification of ${ }^{68} \mathrm{Ga}$-PSMA-positive left internal iliac pelvic node. Intensity-modulated radiotherapy was used to focally increase dose to gross disease to beyond 65 Gy while adequately sparing normal organs at risk. Dose-color-wash displays simulate dose on CT simulation scan with color scale of blue (45 Gy) to red (72 Gy). Dose-volume histograms are plotted with bin doses along horizontal axis and percentage of structure that receives dose greater than or equal to that dose on vertical axis. Each line on dose-volume histogram represents a particular volume (e.g., CTV and relevant organs at risk). 


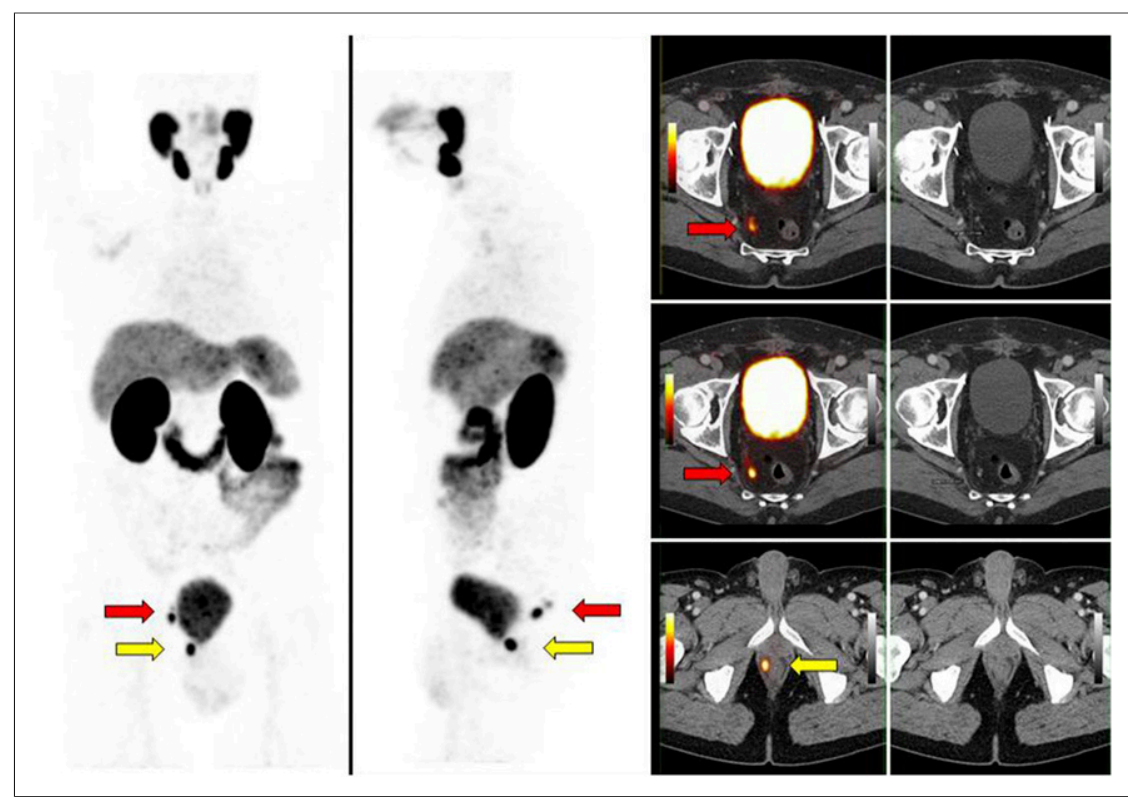

FIGURE 3. Impact of ${ }^{68} \mathrm{Ga}$-PSMA PET/CT on target volumes. Patient with biochemical recurrence (PSA level, $0.81 \mathrm{ng} / \mathrm{mL}$ ) 1 y after radical prostatectomy (Gleason score, 9) was referred for SRT. ${ }^{68} \mathrm{Ga}-\mathrm{PSMA}$ PET showed focal ${ }^{68} \mathrm{Ga}-\mathrm{PSMA}$ uptake in right side of prostate bed (yellow arrows), with nodular tissue-thickening on CT. In addition, ${ }^{68} \mathrm{Ga}-\mathrm{PSMA}$ PET revealed focal ${ }^{68} \mathrm{Ga}-\mathrm{PSMA}$ uptake in 2 right perirectal subcentimeter lymph nodes (short axis, $4 \mathrm{~mm}$; red arrows). Perirectal nodes are not covered by standard SRT and would not have been suspected to harbor recurrent disease based on CT. SRT volumes were expanded to encompass perirectal nodal region.

pelvic nodes (50). The RTOG (51), European Organisation for Research and Treatment of Cancer (52), and the Australian and New Zealand Radiation Oncology Genito-Urinary Group (53) have published guidelines for contouring of the prostate bed. These consensus CTVs are used in current clinical trials and guide routine care.

In both the definitive and the salvage settings, the value of including radiographically negative pelvic nodes is unclear and the subject of current randomized trials (RTOG 0924, RTOG 0534, NCT00567580). In practice, many radiation oncologists include pelvic nodes for high-risk patients (typically, patients with any of

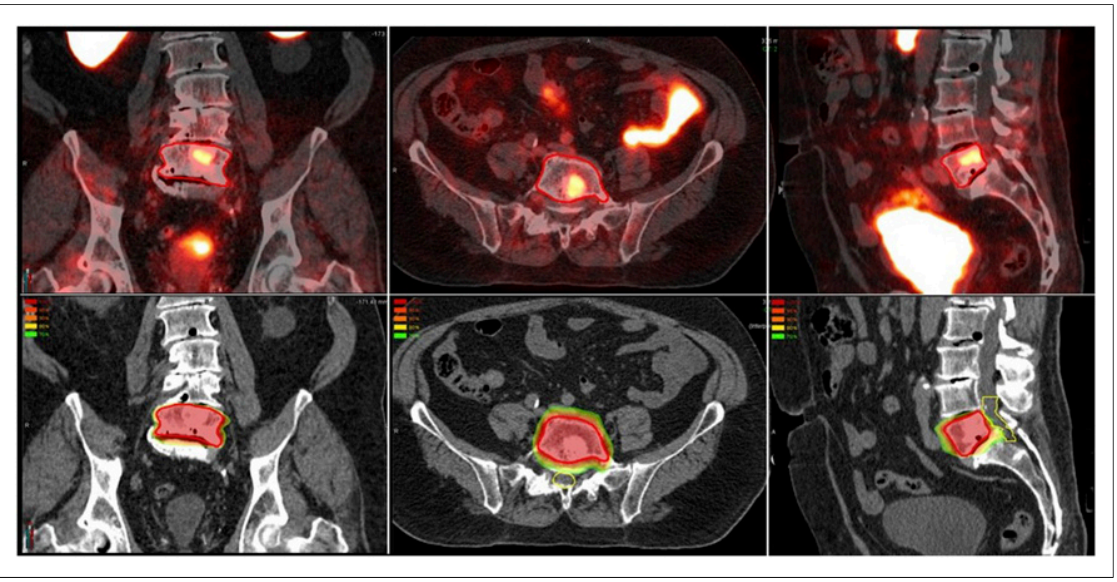

FIGURE 4. ${ }^{68} \mathrm{Ga}-\mathrm{PSMA} P \mathrm{PET} / \mathrm{CT}$ identified solitary L5 metastasis in patient with recurrent prostate cancer after prostatectomy and PSA level of 1 . SBRT was used to deliver 18 Gy in single fraction to solitary metastasis. Dose-color-wash shows that $100 \%$ of prescribed dose covered target volume while sparing cauda equine (yellow contours). the following: initial PSA level $>20$, clinical or radiographic $\mathrm{T}$ stage 3 or higher, Gleason score 8 or higher, rapid PSA doubling time) in both the definitive and the salvage settings. In patients with radiographic evidence of gross tumor within the nodes, the prostate bed, or the prostate itself, a higher dose can be prescribed to cover the gross tumor. This can be accomplished either by the techniques of simultaneous integrated boost (delivering a higher dose to the gross tumor in each fraction) or sequential boost (delivering extra fractions of dose to the gross tumor), or a boost delivered by brachytherapy (temporary or permanent implantation of radioactive seeds).

Incorporation of PET/CT may affect radiotherapy planning in numerous ways. First, PET/CT-defined gross disease within a target volume can be prescribed a higher dose. Figure 2 shows a typical SRT plan for a patient with recurrent prostate cancer and for a patient in whom a ${ }^{68} \mathrm{Ga}$-PSMApositive left-sided internal iliac node received a higher dose than the surrounding pelvic nodal volume. The dose is displayed as a heat map. The dose-volume histograms show the dose that covers a given volume percentage of each delineated volume. The figure shows that $100 \%$ of the ${ }^{68} \mathrm{Ga}$-PSMA-positive node (plus a margin) received more than 65 Gy (dotted line) whereas $100 \%$ of the total pelvic nodal volume received 45 Gy (solid purple line).

Second, CTVs can be expanded to encompass areas of disease not seen by current first-line imaging and not normally targeted by consensus CTVs (Fig. 3). Third, evidence of metastatic disease indicates that local therapy alone would not offer cure. In the setting of oligometastatic disease (limited metastatic disease burden, variously interpreted to mean up to 3 or 5 distinct sites), many physicians offer metastasis-directed therapy aimed at local ablation of the metastases (Figs. 4-6). Metastasis-directed therapy is the subject of numerous current clinical trials (54). Finally, in some cases where PET/CT shows unexpected diffuse metastatic disease, radiotherapy may be considered futile and abandoned.

\section{POTENTIAL IMPACT OF PET/CT ON DEFINITIVE PROSTATE RADIOTHERAPY}

Several studies have assessed the impact of molecular PET/CT imaging on definitive prostate radiotherapy planning (Table 1). López et al. conducted a retrospective analysis on the impact of ${ }^{11} \mathrm{C}$-choline PET/ CT on definitive prostate radiotherapy in 9 patients (55). Four of the 9 patients had a change in contouring and prescribed dose. Two had extension of volumes to include additional nodal regions that were not initially targeted. One received metastasis-directed therapy to a solitary bone metastasis in addition 


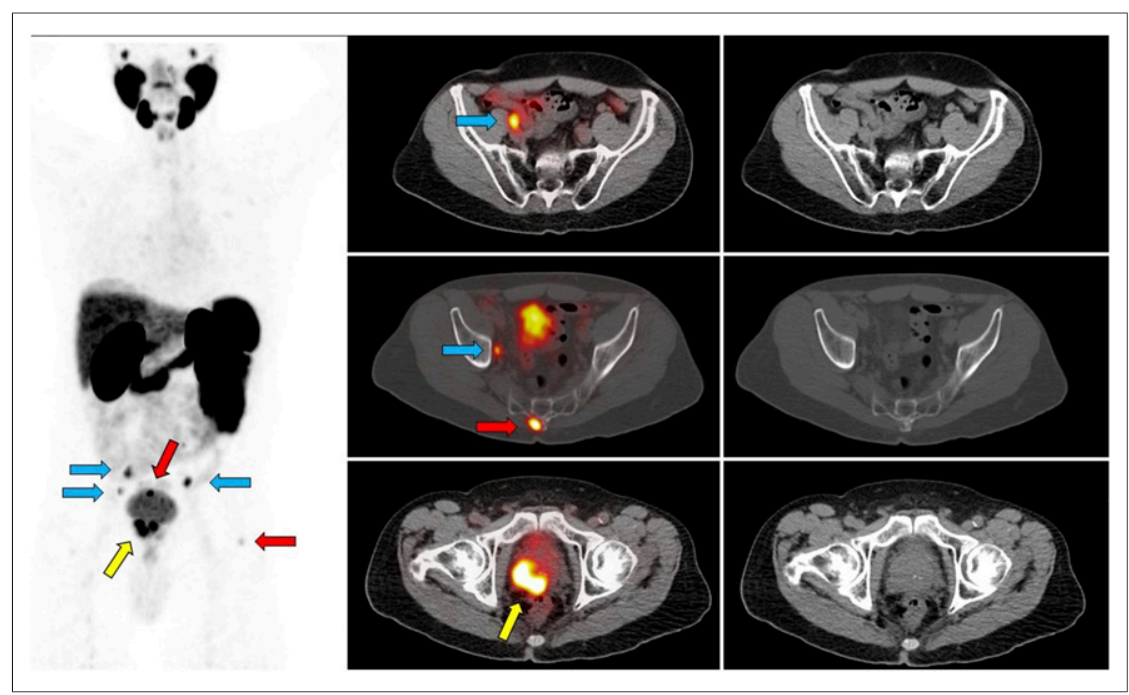

FIGURE 5. Impact of ${ }^{68} \mathrm{Ga}$-PSMA PET/CT on initial management of high-risk prostate cancer. A 77-y-old man with newly diagnosed prostate cancer (initial PSA level, 7.1; Gleason score, $4+5=$ 9) underwent MRI showing right posterolateral prostate lesion with gross extracapsular extension and right seminal vesicle invasion. Bone scan was negative. ${ }^{68} \mathrm{Ga}-\mathrm{PSMA} \mathrm{PET} / \mathrm{CT}$ showed intense ${ }^{68} \mathrm{Ga}$-PSMA uptake in prostate with seminal vesicle invasion (yellow arrows), ${ }^{68} \mathrm{Ga}-\mathrm{PSMA}$-positive subcentimeter external iliac lymph nodes (blue arrows), and focal ${ }^{68} \mathrm{Ga}-\mathrm{PSMA}$ uptake in 2 bone lesions (red arrows). Patient was staged as hormone-sensitive oligometastatic M1b and offered SBRT to 2 bone metastases in addition to radiotherapy to prostate and pelvic nodes with concurrent androgen deprivation therapy.

to treatment of the prostate and nodes. One patient was downstaged because of lack of ${ }^{11} \mathrm{C}$-choline uptake in a suspected metastasis seen on current first-line imaging. Kuang et al. (56) reported on the feasibility of focal dose escalation to PET-defined intraprostatic lesions in 30 patients who underwent ${ }^{18} \mathrm{~F}$-choline $\mathrm{PET} / \mathrm{CT}$ before radiation planning. The investigators showed that focal escalations to $105 \mathrm{~Gy}$ within a prostate CTV receiving $79 \mathrm{~Gy}$ was dosimetrically feasible with adequate protection of normal tissue. Vees et al. evaluated 19 high-risk prostate cancer patients who underwent both ${ }^{18} \mathrm{~F}$-choline PET/CT and sentinel node

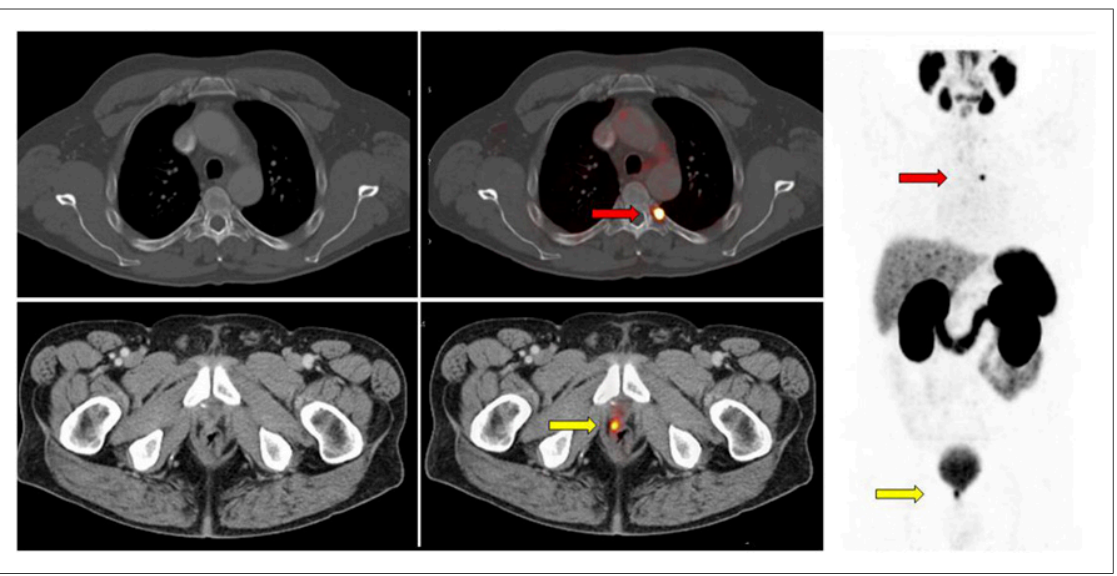

FIGURE 6. Patient with biochemical recurrence (PSA level, $1.85 \mathrm{ng} / \mathrm{mL}$ ) 7 y after radical prostatectomy (Gleason score, 7 ; pT2c) underwent ${ }^{68} \mathrm{Ga}$-PSMA PET/CT, which showed focal ${ }^{68} \mathrm{Ga}-$ PSMA uptake in right side of prostate bed (yellow arrows) and intense focal ${ }^{68} \mathrm{Ga}-\mathrm{PSMA}$ uptake in proximal portion of left fifth rib (red arrows). Patient was offered metastasis-directed SBRT in addition to SRT to prostate bed and nodes.
SPECT (57). ${ }^{18}$ F-choline PET/CT identified 2 nodes that were within standard CTVs. These positive nodes were treated with an escalated dose. Notably, sentinel node SPECT/CT identified 104 nodes, 27 of which would not have been included in consensus CTVs.

Zamboglou et al. reported on the feasibility of boosting ${ }^{68} \mathrm{Ga}$-PSMA-defined intraprostatic lesions to 95 Gy within a prostate receiving $77 \mathrm{~Gy}$ in 10 patients (58). The same group also reported a concordance between ${ }^{68} \mathrm{Ga}$-PSMA PET/CT and multiparametric MRI on intraprostatic disease (59). Dewes et al. reported on 15 patients who were treated with radiotherapy and underwent ${ }^{68} \mathrm{Ga}$-PSMA PET/CT before planning (60). The ${ }^{68} \mathrm{Ga}-\mathrm{PSMA}$ PET/CT changed the TNM stage in 8 of the 15 patients. Modifications of CTVs and changes in the prescribed dose occurred in 5 and 12 patients, respectively. Two patients with suspected metastatic disease from a prior ${ }^{11} \mathrm{C}$-choline scan were downstaged. Sterzing et al. reported on 15 patients who underwent ${ }^{68} \mathrm{Ga}$-PSMA PET/CT for radiotherapy planning (61). Four patients had a change in TNM staging resulting in a change in CTV or prescription.

Randomized, prospective investigations evaluating the impact of PET/CT on definitive prostate radiotherapy planning are lacking. The recent phase III ASCENDE-RT trial of patients with mostly high-risk prostate cancer treated with a combination of radiotherapy and androgen deprivation showed 9-y progressionfree and metastasis-free survivals of $73 \%$ and $87 \%$, respectively (62). The long natural history of prostate cancer and the success rates of definitive radiotherapy in even high-risk patients (62) require large patient numbers to power a trial to detect an improvement in metastasis-free survival. A biochemical progression-free survival primary endpoint, often used in trials in the localized setting, would require fewer patients.

\section{POTENTIAL IMPACT OF PET/CT ON SRT}

Several studies assessed the impact of molecular PET/CT imaging on SRT planning (Table 2).

Souvatzoglou et al. conducted a retrospective study on 37 patients with biochemical recurrence (median PSA level, $0.5 \mathrm{ng} / \mathrm{mL}$ ) after radical prostatectomy who underwent ${ }^{11} \mathrm{C}$-choline PET/CT. ${ }^{11} \mathrm{C}$ choline PET/CT was positive in $30 \%$ of patients, with 5 patients having recurrence in the pelvic nodes and 6 within the prostate bed (63). All patients were initially planned to undergo SRT to the prostate bed alone; the ${ }^{11} \mathrm{C}$-choline PET indicated inclusion of the pelvic nodes in $13.5 \%$ of patients. Würschmidt et al. similarly reported on 18 


\begin{tabular}{|c|c|c|c|c|c|c|c|}
\hline \multirow[b]{2}{*}{ Author } & \multirow[b]{2}{*}{ Year } & \multirow{2}{*}{$\begin{array}{l}\mathrm{PET} / \mathrm{CT} \\
\text { probe }\end{array}$} & \multirow{2}{*}{$\begin{array}{l}\text { Median PSA } \\
\text { level (ng/mL) }\end{array}$} & \multirow[b]{2}{*}{ Patients $(n)$} & \multicolumn{2}{|c|}{$\begin{array}{l}\text { PET- } \\
\text { positive }\end{array}$} & \multirow{2}{*}{$\begin{array}{c}\text { Change in radiotherapy } \\
\text { plan (\%) }\end{array}$} \\
\hline & & & & & $n$ & $\%$ & \\
\hline Würschmidt & 2011 & ${ }^{18} \mathrm{~F}$-choline & 10.4 (range, 2.5-731) & 7 & 7 & 100 & 28.50 \\
\hline Vees & 2012 & ${ }^{18} \mathrm{~F}$-choline & 30.5 (range, 6.4-66.5) & 19 & NA & NA & 22 \\
\hline Jereczek-Fossa & 2014 & ${ }^{11} \mathrm{C}$-choline & NA & 16 & NA & NA & 12.50 \\
\hline Garcia & 2015 & ${ }^{11} \mathrm{C}$-choline & NA (range, 6.3-30.4) & 61 & 61 & 100 & 24.50 \\
\hline López & 2014 & ${ }^{11} \mathrm{C}$-choline & 18.18 (range, 4.90-55.40) & 9 & NA & NA & 44 \\
\hline Alongi & 2015 & ${ }^{18} \mathrm{~F}$-choline & 6.5 (range, 4.1-143) & 60 & 57 & 95 & 21.60 \\
\hline Sterzing & 2016 & ${ }^{68} \mathrm{Ga}-\mathrm{PSMA}$ & 7.04 (range, 0.28-45) & 15 & 9 & 60 & 26.50 \\
\hline Dewes & 2016 & ${ }^{68} \mathrm{Ga}-\mathrm{PSMA}$ & 13.5 (range, 8.2-63.9) & 15 & 15 & 100 & 33.30 \\
\hline
\end{tabular}

patients with biochemical recurrence (median PSA level, $1.9 \mathrm{ng} / \mathrm{mL}$ ) who underwent ${ }^{18} \mathrm{~F}$-choline PET/CT (64). All patients were initially planned to undergo SRT directed to the prostate bed alone. ${ }^{18} \mathrm{~F}$-choline PET/CT was positive in $87.5 \%$ of patients and affected SRT through dose escalation or inclusion of pelvic nodes in all but one patient. Ceci et al. reported that $62 \%$ of 95 patients with biochemical recurrence after prostatectomy (median PSA level, $1.6 \mathrm{ng} / \mathrm{mL}$ ) had a positive ${ }^{11} \mathrm{C}$-choline PET/CT result, with $31.5 \%$ of patients having a change in target volumes and $15.8 \%$ having the planned SRT not delivered (because of distant metastases), consequent to the PET findings (65). Castellucci et al. reported on 605 patients with biochemical recurrence after radical prostatectomy (19 of whom also received adjuvant prostate bed radiotherapy [median PSA level, $1.07 \mathrm{ng} / \mathrm{mL}$; range, $0.2-2 \mathrm{ng} / \mathrm{mL}$ ]) who underwent ${ }^{11} \mathrm{C}$-choline PET/CT before planning of SRT (66). ${ }^{11} \mathrm{C}$ choline PET/CT was positive in $28.5 \%$ of patients, with $14.5 \%$ of patients showing evidence of distant metastases. ${ }^{11} \mathrm{C}$-choline PET/CT changed the planned SRT in $23 \%$ of patients, of whom $14.7 \%$ did not undergo the initially planned treatment because of the presence of distant disease. Jereczek-Fossa et al. reported on 60 patients with biochemical failure after radical prostatectomy ( 5 of whom were on long-term androgen deprivation therapy with evidence of castration resistance) who underwent ${ }^{11} \mathrm{C}$-choline PET/CT for SRT planning (median PSA level, $1.1 \mathrm{ng} / \mathrm{mL})(67) .{ }^{11} \mathrm{C}$-choline PET/ CT was positive in $51 \%$, and all patients with a positive scan and recurrent disease in the pelvis had the recurrent disease focus boosted to $80 \mathrm{~Gy}$ in addition to irradiation of the prostate bed and pelvic nodes. Toxicity was deemed acceptable (acute grade 3 gastrointestinal toxicity was $5 \%$ ). Taken as a group, these studies found that the addition of ${ }^{11} \mathrm{C}$-choline PET to SRT planning changed the initial plan in 357 of 1,083 patients (33\%) (63-70). The main limitation of these studies is that the median PSA at the time of ${ }^{11} \mathrm{C}$-choline PET was significantly higher than the PSA threshold when SRT is commonly initiated. The success rate of SRT decreases with increasing PSA at the time of SRT. Most physicians initiate SRT when the PSA level is less than $1 \mathrm{ng} / \mathrm{mL}$ or, preferably, at or below $0.2 \mathrm{ng} / \mathrm{mL}$ (71). Therefore, imaging that detects disease at or below these thresholds has the best chance to affect SRT.
For ${ }^{68} \mathrm{Ga}$-PSMA PET/CT, detection rates of about $50 \%$ are reported even at PSA levels of less than $0.5 \mathrm{ng} / \mathrm{mL}$ (72), which is low enough to affect target volume delineations for routine SRT. The potential impact of ${ }^{68} \mathrm{Ga}$-PSMA PET/CT on radiotherapy planning has been assessed in 7 studies. Shakespeare et al. reported that ${ }^{68} \mathrm{Ga}$-PSMA PET/CT changed radiotherapy management in $46 \%$ of their patient series (which included primary radiotherapy, postprostatectomy SRT, and postprimary radiotherapy salvaged with additional radiotherapy) (73). Sterzing et al. reported on 42 patients with biochemical recurrence after prostatectomy (median PSA level, $2.8 \mathrm{ng} / \mathrm{mL}$ ) who underwent ${ }^{68} \mathrm{Ga}$-PSMA PET/ $\mathrm{CT}$. The PET results had an impact on radiotherapy management in $51 \%$ of the patients (61). Albisinni et al. reported an impact on subsequent management in 99 of 131 patients (76\%) with a rising PSA level after various treatments with curative intent (surgery, radiotherapy, high-intensity focused ultrasound) (74). Bluemel et al. reported on 45 patients with biochemical recurrence after prostatectomy who underwent ${ }^{68} \mathrm{Ga}$-PSMA PET/CT (44). The scan was positive in $53.3 \%$ of patients, resulting in a change in SRT for $42.2 \%$ of all patients. These changes included expansion of the target volumes, dose escalations, or elimination of SRT entirely in $47 \%, 32 \%$, and $10 \%$ of patients, respectively. $\mathrm{Habl}$ et al. reported on 83 patients with biochemical recurrence after prostatectomy who underwent ${ }^{68} \mathrm{Ga}$-PSMA PET/CT before SRT (median PSA level, $0.69 \mathrm{ng} / \mathrm{mL}$ ) (72). PET was positive in $71 \%$ of patients, affecting the SRT plan in $56.5 \%$. Habl et al. reported on 31 patients with ${ }^{68} \mathrm{Ga}$-PSMA-positive lymph nodes discovered before initiation of SRT and found that $40 \%$ of the ${ }^{68} \mathrm{Ga}$-PSMA-positive pelvic lymph nodes were not covered by the standard RTOG CTVs. Consequently, the ${ }^{68} \mathrm{Ga}$-PSMA PET/ CT resulted in SRT planning changes in $87 \%$ (dose escalation, expansion of target volumes, and addition of metastasis-directed stereotactic body radiation therapy [SBRT] in $51.5 \%, 40 \%$, and $3 \%$ of patients, respectively) (72). Taken as a group, the pooled median rate of impact of ${ }^{68} \mathrm{Ga}$-PSMA PET/CT on SRT planning is $46 \%$ (range, $34.5 \%-87 \%$ ). The primary limitations of these reports are the inhomogeneity of the patients, inconsistent description of anatomic patterns of relapse, and wide range of PSA values at the time of the ${ }^{68} \mathrm{Ga}$-PSMA PET/CT exam $(44,61,72-76)$. In our 
TABLE 2

Studies That Assessed Impact of Molecular PET/CT on SRT Planning

\begin{tabular}{|c|c|c|c|c|c|c|c|c|}
\hline Author & Year & $\begin{array}{l}\mathrm{PET} / \mathrm{CT} \\
\text { probe }\end{array}$ & $\begin{array}{l}\text { Median } \\
\text { PSA level } \\
(\mathrm{ng} / \mathrm{mL})\end{array}$ & $\begin{array}{l}\text { Patients } \\
\text { (n) }\end{array}$ & $\begin{array}{l}\text { PET- } \\
\text { positive }\end{array}$ & $\begin{array}{l}\text { Extrapelvic } \\
\text { PET- } \\
\text { positive }\end{array}$ & $\begin{array}{l}\text { Any SRT } \\
\text { planning } \\
\text { change }\end{array}$ & $\begin{array}{l}\text { Radiotherapy } \\
\text { considered } \\
\text { futile }\end{array}$ \\
\hline Souvatzoglou & 2011 & ${ }^{11} \mathrm{C}$-choline & $\begin{array}{l}0.5 \text { (range, } \\
0.25-12.3 \text { ) }\end{array}$ & 37 & $30 \%$ & $0 \%$ & $13.5 \%$ & $0 \%$ \\
\hline Würschmidt & 2011 & ${ }^{18} \mathrm{~F}$-choline & $\begin{array}{c}1.9 \text { (range, } \\
0.42-4.8 \text { ) }\end{array}$ & 16 & $87.5 \%$ & $6.5 \%$ & $81.5 \%$ & $6.5 \%$ \\
\hline Ceci & 2014 & ${ }^{11} \mathrm{C}$-choline & $\begin{array}{c}1.6 \text { (range, } \\
0.2-7.1 \text { ) }\end{array}$ & 95 & $62 \%$ & $20 \%$ & $47.5 \%$ & $15.8 \%$ \\
\hline Castelluci & 2014 & ${ }^{11} \mathrm{C}$-choline & $\begin{array}{l}1.1 \text { (range, } \\
0.2-2 \text { ) }\end{array}$ & 605 & $28.5 \%$ & $14.5 \%$ & $23 \%$ & $14.7 \%$ \\
\hline Goldstein & 2017 & ${ }^{11} \mathrm{C}$-choline & $\begin{array}{l}2 \text { (range, } \\
0.16-79 \text { ) }\end{array}$ & 6 & NA & & $33.5 \%$ & $0 \%$ \\
\hline $\begin{array}{l}\text { Jereczek- } \\
\text { Fossa }\end{array}$ & 2014 & ${ }^{11} \mathrm{C}$-choline & $\begin{array}{l}1.1 \text { (range, } \\
0.2-16.2 \text { ) }\end{array}$ & 55 & $51 \%$ & NA & $31 \%$ & NA \\
\hline Shakespeare & 2015 & ${ }^{68} \mathrm{Ga}-\mathrm{PSMA}$ & $\begin{array}{l}1.1 \text { (range, } \\
0.017-20.4 \text { ) }\end{array}$ & 18 & NA & & $46 \%$ & NA \\
\hline van Leeuwen & 2015 & ${ }^{68} \mathrm{Ga}-\mathrm{PSMA}$ & $\begin{array}{l}0.2 \text { (range, } \\
0.05-0.99 \text { ) }\end{array}$ & 70 & $54.5 \%$ & $5.5 \%$ & $34.5 \%$ & $7.1 \%$ \\
\hline Sobol & 2016 & $\begin{array}{l}{ }^{11} \mathrm{C} \text {-choline }+ \\
\text { multiparametric } \\
\text { MRI }\end{array}$ & $\begin{array}{c}2.3 \text { (range, } \\
1.4-5.5 \text { ) }\end{array}$ & 260 & $77.5 \%$ & $26.5 \%$ & $51.5 \%$ & $26.5 \%$ \\
\hline Sterzing & 2016 & ${ }^{68} \mathrm{Ga}-\mathrm{PSMA}$ & $\begin{array}{l}2.8 \text { (range, } \\
0.16-113 \text { ) }\end{array}$ & 42 & $59.5 \%$ & NA & $60.5 \%$ & NA \\
\hline Albisinni & 2016 & ${ }^{68} \mathrm{Ga}-\mathrm{PSMA}$ & $\begin{array}{l}2.2 \text { (range, } \\
0.72-6.7 \text { ) }\end{array}$ & 48 & NA & & $76 \%$ & NA \\
\hline Bluemel & 2016 & ${ }^{68} \mathrm{Ga}-\mathrm{PSMA}$ & $\begin{array}{r}0.67 \text { (range, } \\
0.10-11.2 \text { ) }\end{array}$ & 45 & $53.5 \%$ & $9 \%$ & $42 \%$ & $4.4 \%$ \\
\hline Lamanna & 2017 & $\begin{array}{l}{ }^{18} \mathrm{~F} \text {-choline/ } \\
{ }^{11} \mathrm{C} \text {-acetate }\end{array}$ & $\begin{array}{l}1.9 \text { (range, } \\
0.3-3 \text { ) }\end{array}$ & 9 & NA & $0 \%$ & $22 \%$ & $0 \%$ \\
\hline Akin-Akintayo & 2017 & ${ }^{18} \mathrm{~F}$-fluciclovine & $\begin{array}{l}0.55 \text { (range, } \\
0.07-11.2 \text { ) }\end{array}$ & 42 & $81 \%$ & $5 \%$ & $40.5 \%$ & $4.8 \%$ \\
\hline Habl & 2017 & ${ }^{68} \mathrm{Ga}-\mathrm{PSMA}$ & $\begin{array}{r}0.69 \text { (range, } \\
0.09-14.7 \text { ) }\end{array}$ & 83 & $71 \%$ & $9.5 \%$ & $56.5 \%$ & $0 \%$ \\
\hline Schiller & 2017 & ${ }^{68} \mathrm{Ga}-\mathrm{PSMA}$ & $\begin{array}{r}0.71 \text { (range, } \\
0.12-14.7 \text { ) }\end{array}$ & 31 & $1 \%$ & $3 \%$ & $87 \%$ & $0 \%$ \\
\hline Calais & 2018 & ${ }^{68} \mathrm{Ga}-\mathrm{PSMA}$ & $0.48(0.03-1.0)$ & 270 & $49 \%$ & $12 \%$ & $19 \%$ & $2.5 \%$ \\
\hline
\end{tabular}

recent study on a homogeneous cohort of 270 patients with biochemical failure after radical prostatectomy at low PSA values $(<1 \mathrm{ng} / \mathrm{mL}$; median PSA, $0.48 \mathrm{ng} / \mathrm{mL}$ ), ${ }^{68} \mathrm{Ga}$-PSMA PET/CT detected lesions not covered by planning based on standard RTOG volumes covering both the prostate bed and the pelvic lymph nodes in $19 \%$ of all patients (40\% of patients with a positive ${ }^{68} \mathrm{Ga}$-PSMA PET/CT), thus implying a major impact on SRT planning (77).

\section{POTENTIAL IMPACT OF PET/CT ON SYSTEMIC STAGING AND METASTASIS-DIRECTED THERAPIES}

Current first-line imaging was used in the many clinical trials that guide current prostate treatment paradigms. As PET/CT becomes incorporated into routine care, it is likely that many patients staged N0 or M0 by current first-line imaging will be more accurately staged as N1 or M1. Roach et al. recently reported on the results of ${ }^{68} \mathrm{Ga}$-PSMA PET/CT in 431 patients with primary and recurrent prostate cancer with negative or equivocal current first-line imaging (78). The PET scans revealed previously unknown nodal disease and distant metastatic disease in $39 \%$ and $16 \%$ of patients, respectively (78).

It is likely that many patients upstaged by PET/CT will have limited metastatic disease burden. For patients with radiographic evidence of $\mathrm{N} 1$ disease at initial staging, current guidelines include radiotherapy of the prostate and pelvic nodes with long-term androgen deprivation therapy (79). Treatment of patients with radiographic evidence of $\mathrm{N} 1$ disease after local failure is less clear. The primary therapy for prostate cancer patients with M1 disease is androgen 


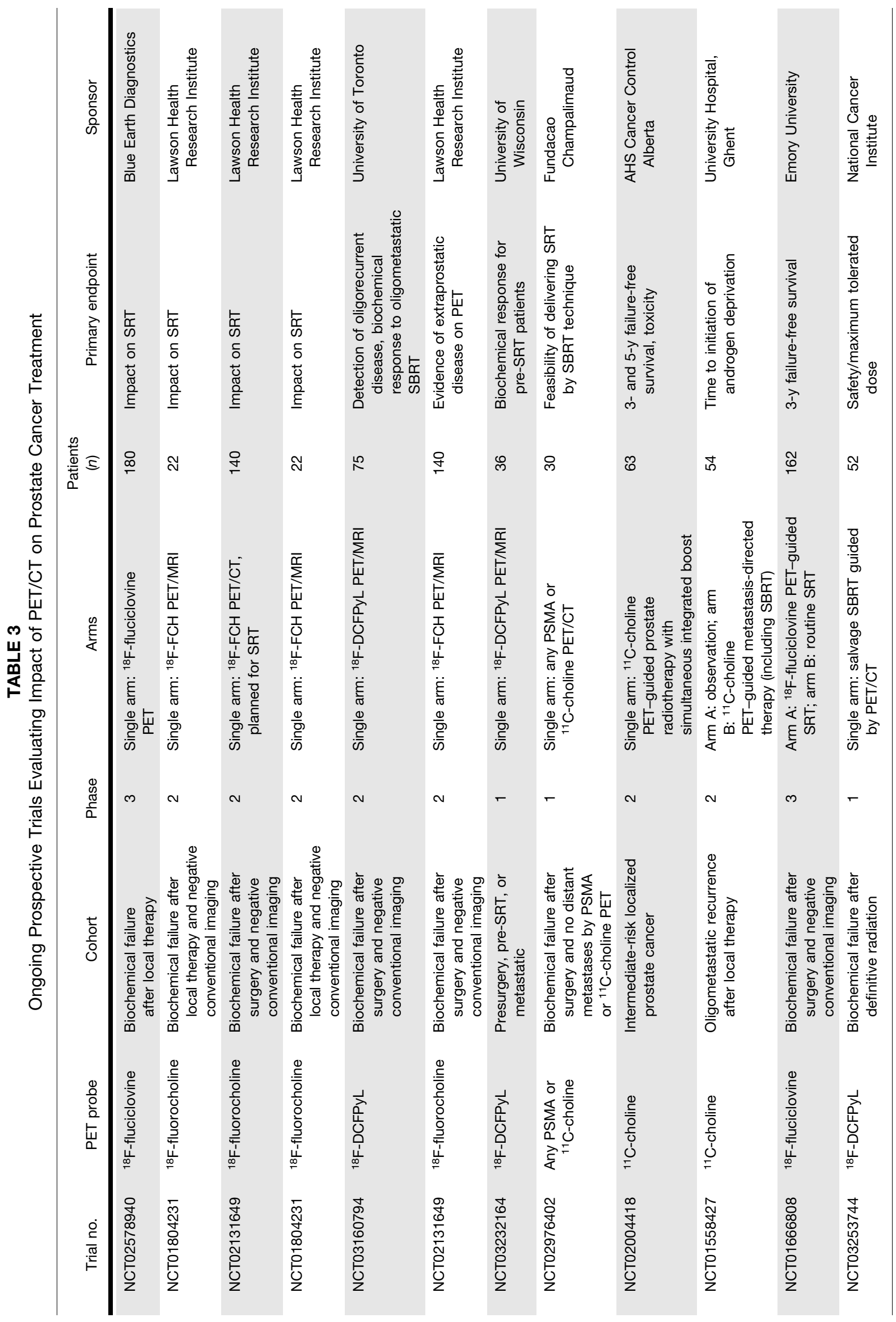

564 The Journal of Nuclear Medicine • Vol. 59 • No. 4 • April 2018 
deprivation therapy. However, to many clinicians, it seems reasonable to approach a patient with limited metastatic disease (oligometastatic) differently from a patient with diffuse metastatic disease. (Investigators have variously defined oligometastatic prostate cancer as having at most 3 or 5 distinct distant metastases.) Metastasisdirected therapy, via SBRT or metastatectomy, with or without systemic therapy is a strategy under evaluation in several ongoing and planned prospective trials (80). Whether prostate cancer patients with oligometastatic disease ultimately benefit from a therapeutic strategy different from that given to patients with diffuse metastatic disease remains unknown. In any case, identification of these patients is likely to increase substantially as clinicians adopt PET/CT for initial and recurrent staging.

\section{PROSPECTIVE TRIALS EVALUATING IMPACT OF PET/CT ON PROSTATE RADIOTHERAPY PLANNING}

Several ongoing prospective trials are evaluating the impact of PET/CT on prostate cancer treatment in a variety of clinical settings (Table 3 ). In the setting of biochemical recurrence, the FALCON trial (NCT02578940) is evaluating the impact of ${ }^{18} \mathrm{~F}$ fluciclovine PET/CT on SRT management. The Lawson Health Research Institute in Ontario is conducting 3 trials evaluating the effect of ${ }^{18} \mathrm{~F}$-choline PET/CT on SRT management in patients with negative results on current first-line imaging (NCT01804231, NCT02131649, NCT01804231). The University of Toronto is also conducting a single-arm trial of ${ }^{18} \mathrm{~F}$-DCFPyL PET/CT in patients with biochemical failure after surgery and negative results on current first-line imaging (NCT03160794). The endpoints are detection of oligorecurrent disease and biochemical response to oligometastatic SBRT offered to patients with detectable disease amenable to this treatment.

Two single-arm prospective trials are evaluating the impact of PET/CT on SRT. The University of Wisconsin is prospectively evaluating ${ }^{18} \mathrm{~F}$-DCFPyL PET/CT in 36 patients planned for surgery or SRT (NCT03232164). The Champalimaud Foundation in Portugal is conducting a feasibility trial of SRT delivered by SBRT technique in patients planned to undergo either PSMA or ${ }^{11} \mathrm{C}$-choline PET/CT (NCT02976402). A phase II trial of ${ }^{11} \mathrm{C}$-choline PET/CTguided definitive radiotherapy in 63 patients, including focal dose escalation to intraprostatic foci, is being conducted by the Alberta Health Services, CancerControl Alberta (NCT02004418). The NCI is conducting a prospective phase I trial of ${ }^{18} \mathrm{~F}$-DCFPyL PET/CTguided SBRT for locally recurrent prostate cancer after definitive radiotherapy (NCT03253744).

In the oligorecurrent metastatic setting, the STOMP trial (NCT01558427) at the University Hospital, Ghent, randomized patients restaged with ${ }^{11} \mathrm{C}$-choline PET to metastasis-directed therapy versus observation. The primary endpoint was time to initiation of androgen deprivation therapy. Metastasis-directed therapy increased androgen deprivation therapy-free survival from 13 to 21 months (hazard ratio, 0.60; log-rank $P=0.11$ ) (81).

Jani et al. at Emory University are conducting a prospective phase III trial evaluating the use of ${ }^{18} \mathrm{~F}$-fluciclovine PET/CT to guide and improve outcomes in patients planned for SRT (NCT01666808) (82). In this ongoing trial, 162 patients with a rising PSA level after radical prostatectomy, and with current first-line imaging negative for distant metastases, are being randomized to routine SRT guided by current first-line imaging versus SRT guided by abdominal-pelvic ${ }^{18} \mathrm{~F}$-fluciclovine PET/CT. The primary endpoint is biochemical control. Although no cancer control outcome data are yet available, the investigators have reported the impact of ${ }^{18} \mathrm{~F}$-fluciclovine PET/CT on planning for patients randomized to the experimental arm and the acute toxicity of SRT guided by PET/CT compared with SRT guided by current first-line imaging (82). Treatment of patients randomized to the PET/CT arm was planned first with and then without information from PET. Target volumes were modified in 31 of the first 41 patients $(73 \%)$ in the PET arm (median PSA level, $0.43 \mathrm{ng} / \mathrm{mL}$ ). Doses to critical organs at risk (rectum, bowel, bladder) were not significantly different for the PET-assisted treatment volumes, despite the larger volumes. Acute toxicity also did not differ between the treatment arms, suggesting that the additional treatment volumes guided by PET may not increase long-term toxicity. Additional follow-up is required to assess the impact of ${ }^{18} \mathrm{~F}$-fluciclovine PET/ CT on biochemical control and late toxicity.

\section{CONCLUSION}

Conventional systemic imaging of prostate cancer suffers from poor sensitivity and underestimates the extent of disease in many patients. PET/CT using ${ }^{11} \mathrm{C}$ - or ${ }^{18} \mathrm{~F}$-choline, ${ }^{11} \mathrm{C}$-acetate, ${ }^{18} \mathrm{~F}$-fluciclovine, or ${ }^{68} \mathrm{Ga}$ - or ${ }^{18} \mathrm{~F}$-ligands that bind PSMA improve imaging accuracy. Of these probes, the PSMA ligands are the most sensitive and specific. Incorporation of PET/CT into current practice is expected to upstage a substantial proportion of patients, with clear implications for current treatment paradigms. Modern radiotherapy planning is immediately amenable to integration of these PET scans. Retrospective assessments support the hypothesis that integration of PET/CT into radiotherapy planning could have a meaningful clinical benefit to patients. Results from prospective trials are required to assess this impact.

\section{REFERENCES}

1. Siegel RL, Miller KD, Jemal A. Cancer statistics, 2017. CA Cancer J Clin. 2017;67:7-30.

2. Hamdy FC, Donovan JL, Lane JA, et al. 10-year outcomes after monitoring, surgery, or radiotherapy for localized prostate cancer. $N$ Engl J Med. 2016;375: 1415-1424.

3. King CR. Adjuvant versus salvage radiotherapy for high-risk prostate cancer patients. Semin Radiat Oncol. 2013;23:215-221.

4. Lecouvet FE, Geukens D, Stainier A, et al. Magnetic resonance imaging of the axial skeleton for detecting bone metastases in patients with high-risk prostate cancer: diagnostic and cost-effectiveness and comparison with current detection strategies. J Clin Oncol. 2007;25:3281-3287.

5. Even-Sapir E, Metser U, Mishani E, Lievshitz G, Lerman H, Leibovitch I. The detection of bone metastases in patients with high-risk prostate cancer: ${ }^{99 m} \mathrm{Tc}-\mathrm{MDP}$ planar bone scintigraphy, single- and multi-field-of-view SPECT, ${ }^{18} \mathrm{~F}$-fluoride PET, and ${ }^{18}$ F-fluoride PET/CT. J Nucl Med. 2006;47:287-297.

6. Hövels AM, Heesakkers RA, Adang EM, et al. The diagnostic accuracy of CT and MRI in the staging of pelvic lymph nodes in patients with prostate cancer: a meta-analysis. Clin Radiol. 2008;63:387-395.

7. Cher ML, Bianco FJ, Lam JS, et al. Limited role of radionuclide bone scintigraphy in patients with prostate specific antigen elevations after radical prostatectomy. J Urol. 1998;160:1387-1391.

8. Kane CJ, Amling CL, Johnstone PAS, et al. Limited value of bone scintigraphy and computed tomography in assessing biochemical failure after radical prostatectomy. Urology. 2003;61:607-611.

9. Krämer S, Görich J, Gottfried HW, et al. Sensitivity of computed tomography in detecting local recurrence of prostatic carcinoma following radical prostatectomy. Br J Radiol. 1997;70:995-999.

10. Gill BS, Pai SS, McKenzie S, Beriwal S. Utility of PET for radiotherapy treatment planning. PET Clin. 2015;10:541-554.

11. Vander Heiden MG, Cantley LC, Thompson CB. Understanding the Warburg effect: the metabolic requirements of cell proliferation. Science. 2009;324:1029-1033.

12. Plathow C, Weber WA. Tumor cell metabolism imaging. J Nucl Med. 2008; 49(suppl 2):43S-63S. 
13. Gillies RJ, Robey I, Gatenby RA. Causes and consequences of increased glucose metabolism of cancers. J Nucl Med. 2008;49(suppl 2):24S-42S.

14. Leclerc M, Lartigau E, Lacornerie T, Daisne J-F, Kramar A, Grégoire V. Primary tumor delineation based on ${ }^{18}$ FDG PET for locally advanced head and neck cancer treated by chemo-radiotherapy. Radiother Oncol. 2015;116:87-93.

15. De Ruysscher D, Faivre-Finn C, Moeller D, et al. European Organization for Research and Treatment of Cancer (EORTC) recommendations for planning and delivery of high-dose, high precision radiotherapy for lung cancer. Radiother Oncol. 2017;124:1-10.

16. Konert T, Vogel W, MacManus MP, et al. PET/CT imaging for target volume delineation in curative intent radiotherapy of non-small cell lung cancer: IAEA consensus report 2014. Radiother Oncol. 2015;116:27-34.

17. Herrera FG, Prior JO. The role of PET/CT in cervical cancer. Front Oncol. 2013;3:34.

18. Figura N, Flampouri S, Mendenhall NP, et al. Importance of baseline PET/CT imaging on radiation field design and relapse rates in patients with Hodgkin lymphoma. Adv Radiat Oncol. 2017;2:197-203.

19. Specht L, Yahalom J, Illidge T, et al. Modern radiation therapy for Hodgkin lymphoma: field and dose guidelines from the international lymphoma radiation oncology group (ILROG). Int J Radiat Oncol Biol Phys. 2014;89:854-862.

20. Jadvar H. PET of glucose metabolism and cellular proliferation in prostate cancer. J Nucl Med. 2016;57(suppl 3):25S-29S.

21. Wibmer AG, Burger IA, Sala E, Hricak H, Weber WA, Vargas HA. Molecular imaging of prostate cancer. Radiographics. 2016;36:142-159.

22. Jadvar H. FDG PET in prostate cancer. PET Clin. 2009;4:155-161.

23. FDA approves ${ }^{18} \mathrm{~F}$-fluciclovine and ${ }^{68} \mathrm{Ga}$-DOTATATE products. $\mathrm{J} \mathrm{Nucl} \mathrm{Med}$. 2016;57(8):9N.

24. Calais J, Fendler WP, Herrmann K, Eiber M, Ceci F. Head-to-head comparison of ${ }^{68}$ Ga-PSMA-11 PET/CT and ${ }^{18}$ F-fluciclovine PET/CT in a case series of 10 patients with prostate cancer recurrence. J Nucl Med. December 14, 2017 [Epub ahead of print].

25. Eiber M, Maurer T, Souvatzoglou M, et al. Evaluation of hybrid ${ }^{68}$ Ga-PSMA ligand PET/CT in 248 patients with biochemical recurrence after radical prostatectomy. J Nucl Med. 2015;56:668-674.

26. Perera M, Papa N, Christidis D, et al. Sensitivity, specificity, and predictors of positive ${ }^{68} \mathrm{Ga}$-prostate-specific membrane antigen positron emission tomography in advanced prostate cancer: a systematic review and meta-analysis. Eur Urol. 2016;70:926-937.

27. Gerety EL, Lawrence EM, Wason J, et al. Prospective study evaluating the relative sensitivity of ${ }^{18} \mathrm{~F}-\mathrm{NaF}$ PET/CT for detecting skeletal metastases from renal cell carcinoma in comparison to multidetector CT and ${ }^{99 \mathrm{~m} T c-M D P}$ bone scintigraphy, using an adaptive trial design. Ann Oncol. 2015;26:2113-2118.

28. Wu F, Jamali M, Hatami N, et al. ${ }^{99 \mathrm{~m} T c-M D P}$ scintigraphy vs. ${ }^{18} \mathrm{~F}-\mathrm{NaF}$ PET/CT for detection of skeletal metastases [abstract]. J Nucl Med. 2016;57(suppl 2):599.

29. Even-Sapir E, Metser U, Flusser G, et al. Assessment of malignant skeletal disease: initial experience with ${ }^{18} \mathrm{~F}$-fluoride PET/CT and comparison between ${ }^{18}$ F-fluoride PET and ${ }^{18}$ F-fluoride PET/CT. J Nucl Med. 2004;45:272-278.

30. FDA approves ${ }^{11} \mathrm{C}$-choline for PET in prostate cancer. J Nucl Med. 2012;53 (12): $11 \mathrm{~N}$.

31. Okudaira H, Shikano N, Nishii R, et al. Putative transport mechanism and intracellular fate of trans-1-amino-3- ${ }^{18} \mathrm{~F}$-fluorocyclobutanecarboxylic acid in human prostate cancer. J Nucl Med. 2011;52:822-829.

32. Oka S, Okudaira H, Yoshida Y, Schuster DM, Goodman MM, Shirakami Y. Transport mechanisms of trans-1-amino-3-fluoro $\left[1-{ }^{14} \mathrm{C}\right]$ cyclobutanecarboxylic acid in prostate cancer cells. Nucl Med Biol. 2012;39:109-119.

33. Bach-Gansmo T, Nanni C, Nieh PT, et al. Multisite experience of the safety, detection rate and diagnostic performance of fluciclovine $\left({ }^{18} \mathrm{~F}\right)$ positron emission tomography/computerized tomography imaging in the staging of biochemically recurrent prostate cancer. J Urol. 2017;197:676-683.

34. Nanni C, Zanoni L, Pultrone C, et al. ${ }^{18}$ F-FACBC (anti1-amino-3- ${ }^{18}$ F-fluorocyclobutane-1-carboxylic acid) versus ${ }^{11} \mathrm{C}$-choline PET/CT in prostate cancer relapse: results of a prospective trial. Eur J Nucl Med Mol Imaging. 2016;43:1601-1610.

35. Minner S, Wittmer C, Graefen M, et al. High level PSMA expression is associated with early PSA recurrence in surgically treated prostate cancer. Prostate. 2011;71:281-288.

36. Uprimny C, Kroiss AS, Decristoforo C, et al. ${ }^{68}$ Ga-PSMA-11 PET/CT in primary staging of prostate cancer: PSA and Gleason score predict the intensity of tracer accumulation in the primary tumour. Eur J Nucl Med Mol Imaging. 2017;44: 941-949.

37. Marchal C, Redondo M, Padilla M, et al. Expression of prostate specific membrane antigen (PSMA) in prostatic adenocarcinoma and prostatic intraepithelial neoplasia. Histol Histopathol. 2004;19:715-718.

38. Wright GL, Grob BM, Haley C, et al. Upregulation of prostate-specific membrane antigen after androgen-deprivation therapy. Urology. 1996;48:326-334.
39. Maurer T, Gschwend JE, Rauscher I, et al. Diagnostic efficacy of ${ }^{68}$ galliumPSMA positron emission tomography compared to conventional imaging for lymph node staging of 130 consecutive patients with intermediate to high risk prostate cancer. J Urol. 2016;195:1436-1443.

40. Budäus L, Leyh-Bannurah S-R, Salomon G, et al. Initial experience of ${ }^{68} \mathrm{Ga}-$ PSMA PET/CT imaging in high-risk prostate cancer patients prior to radical prostatectomy. Eur Urol. 2016;69:393-396.

41. Pyka T, Okamoto S, Dahlbender M, et al. Comparison of bone scintigraphy and ${ }^{68} \mathrm{Ga}$-PSMA PET for skeletal staging in prostate cancer. Eur J Nucl Med Mol Imaging. 2016;43:2114-2121.

42. Thomas L, Balmus C, Ahmadzadehfar H, Essler M, Strunk H, Bundschuh RA. Assessment of bone metastases in patients with prostate cancer-a comparison between ${ }^{99 \mathrm{~m} T c-b o n e-s c i n t i g r a p h y}$ and $\left[{ }^{68} \mathrm{Ga}\right] \mathrm{Ga}$-PSMA PET/CT. Pharmaceuticals (Basel). 2017;10:68.

43. Afshar-Oromieh A, Malcher A, Eder M, et al. PET imaging with a $\left[{ }^{68} \mathrm{Ga}\right]$ gallium-labelled PSMA ligand for the diagnosis of prostate cancer: biodistribution in humans and first evaluation of tumour lesions. Eur J Nucl Med Mol Imaging. 2013;40:486-495.

44. Bluemel C, Krebs M, Polat B, et al. ${ }^{68} \mathrm{Ga}-\mathrm{PSMA-PET/CT}$ in patients with biochemical prostate cancer recurrence and negative ${ }^{18} \mathrm{~F}$-choline-PET/CT. Clin Nucl Med. 2016;41:515-521.

45. Schwenck J, Rempp H, Reischl G, et al. Comparison of ${ }^{68} \mathrm{Ga}$-labelled PSMA-11 and ${ }^{11} \mathrm{C}$-choline in the detection of prostate cancer metastases by PET/CT. Eur J Nucl Med Mol Imaging. 2017;44:92-101.

46. Fendler WP, Rahbar K, Herrmann K, Kratochwil C, Eiber M. ${ }^{177}$ Lu-PSMA radioligand therapy for prostate cancer. J Nucl Med. 2017;58:1196-1200.

47. Rahbar K, Ahmadzadehfar H, Kratochwil C, et al. German multicenter study investigating ${ }^{177}$ Lu-PSMA-617 radioligand therapy in advanced prostate cancer patients. J Nucl Med. 2017;58:85-90.

48. Turkbey B, Choyke PL. Multiparametric MRI and prostate cancer diagnosis and risk stratification. Curr Opin Urol. 2012;22:310-315.

49. Le JD, Tan N, Shkolyar E, et al. Multifocality and prostate cancer detection by multiparametric magnetic resonance imaging: correlation with whole-mount histopathology. Eur Urol. 2015;67:569-576.

50. Lawton CAF, Michalski J, El-Naqa I, et al. RTOG GU radiation oncology specialists reach consensus on pelvic lymph node volumes for high-risk prostate cancer. Int J Radiat Oncol Biol Phys. 2009;74:383-387.

51. Michalski JM, Lawton C, El Naqa I, et al. Development of RTOG consensus guidelines for the definition of the clinical target volume for postoperative conformal radiation therapy for prostate cancer. Int J Radiat Oncol Biol Phys. 2010;76:361-368.

52. Poortmans P, Bossi A, Vandeputte K, et al. Guidelines for target volume definition in post-operative radiotherapy for prostate cancer, on behalf of the EORTC Radiation Oncology Group. Radiother Oncol. 2007;84:121-127.

53. Sidhom MA, Kneebone AB, Lehman M, et al. Post-prostatectomy radiation therapy: consensus guidelines of the Australian and New Zealand Radiation Oncology Genito-Urinary Group. Radiother Oncol. 2008;88:10-19.

54. Broughman JR, Chen RC. Management of node-positive and oligometastatic prostate cancer. Semin Radiat Oncol. 2017;27:79-86.

55. López E, Lazo A, Gutiérrez A, Arregui G, Núñez I, Sacchetti A. Influence of ${ }^{11} \mathrm{C}$-choline PET/CT on radiotherapy planning in prostate cancer. Rep Pract Oncol Radiother. 2014;20:104-112.

56. Kuang Y, Wu L, Hirata E, Miyazaki K, Sato M, Kwee SA. Volumetric modulated arc therapy planning for primary prostate cancer with selective intraprostatic boost determined by ${ }^{18}$ F-choline PET/CT. Int J Radiat Oncol Biol Phys. 2015; 91:1017-1025.

57. Vees H, Steiner C, Dipasquale G, et al. Target volume definition in high-risk prostate cancer patients using sentinel node SPECT/CT and ${ }^{18} \mathrm{~F}$-choline PET/CT. Radiat Oncol. 2012;7:134.

58. Zamboglou C, Sachpazidis I, Koubar K, et al. Evaluation of intensity modulated radiation therapy dose painting for localized prostate cancer using ${ }^{68} \mathrm{Ga}-\mathrm{HBED}-$ CC PSMA-PET/CT: a planning study based on histopathology reference. Radiother Oncol. 2017;123:472-477.

59. Zamboglou C, Drendel V, Jilg CA, et al. Comparison of ${ }^{68}$ Ga-HBED-CC PSMA$\mathrm{PET} / \mathrm{CT}$ and multiparametric MRI for gross tumour volume detection in patients with primary prostate cancer based on slice by slice comparison with histopathology. Theranostics. 2017;7:228-237.

60. Dewes S, Schiller K, Sauter K, et al. Integration of ${ }^{68}$ Ga-PSMA-PET imaging in planning of primary definitive radiotherapy in prostate cancer: a retrospective study. Radiat Oncol. 2016;11:73.

61. Sterzing F, Kratochwil C, Fiedler H, et al. ${ }^{68}$ Ga-PSMA-11 PET/CT: a new technique with high potential for the radiotherapeutic management of prostate cancer patients. Eur J Nucl Med Mol Imaging. 2016;43:34-41. 
62. Morris WJ, Tyldesley S, Rodda S, et al. Androgen suppression combined with elective nodal and dose escalated radiation therapy (the ASCENDE-RT trial): an analysis of survival endpoints for a randomized trial comparing a low-dose-rate brachytherapy boost to a dose-escalated external beam boost for high- and intermediate-risk prostate cancer. Int J Radiat Oncol Biol Phys. 2017;98:275-285.

63. Souvatzoglou M, Krause BJ, Pürschel A, et al. Influence of ${ }^{11} \mathrm{C}$-choline PET/CT on the treatment planning for salvage radiation therapy in patients with biochemical recurrence of prostate cancer. Radiother Oncol. 2011;99:193-200.

64. Würschmidt F, Petersen C, Wahl A, Dahle J, Kretschmer M. $\left[{ }^{18}\right.$ F $]$ fluoroethylcholine-PET/CT imaging for radiation treatment planning of recurrent and primary prostate cancer with dose escalation to PET/CT-positive lymph nodes. Radiat Oncol. 2011;6:44.

65. Ceci F, Herrmann K, Castellucci P, et al. Impact of ${ }^{11} \mathrm{C}$-choline PET/CT on clinical decision making in recurrent prostate cancer: results from a retrospective two-centre trial. Eur J Nucl Med Mol Imaging. 2014;41:2222-2231.

66. Castellucci P, Ceci F, Graziani T, et al. Early biochemical relapse after radical prostatectomy: which prostate cancer patients may benefit from a restaging ${ }^{11} \mathrm{C}$ choline PET/CT scan before salvage radiation therapy? J Nucl Med. 2014;55: 1424-1429.

67. Jereczek-Fossa BA, Rodari M, Bonora M, et al. $\left[{ }^{11} \mathrm{C}\right]$ choline PET/CT impacts treatment decision making in patients with prostate cancer referred for radiotherapy. Clin Genitourin Cancer. 2014;12:155-159.

68. Goldstein J, Even-Sapir E, Ben-Haim S, et al. Does choline PET/CT change the management of prostate cancer patients with biochemical failure? Am J Clin Oncol. 2017;40:256-259.

69. Sobol I, Zaid HB, Haloi R, et al. Contemporary mapping of post-prostatectomy prostate cancer relapse with ${ }^{11} \mathrm{C}$-choline positron emission tomography and multiparametric magnetic resonance imaging. J Urol. 2017;197:129-134.

70. Lamanna G, Tabouret-Viaud C, Rager O, et al. Long-term results of a comparative PET/CT and PET/MRI study of ${ }^{11} \mathrm{C}$-acetate and ${ }^{18} \mathrm{~F}$-fluorocholine for restaging of early recurrent prostate cancer. Clin Nucl Med. 2017;42:e242-e246.

71. King CR. The timing of salvage radiotherapy after radical prostatectomy: a systematic review. Int J Radiat Oncol Biol Phys. 2012;84:104-111.

72. Habl G, Sauter K, Schiller K, et al. ${ }^{68} \mathrm{Ga}$-PSMA-PET for radiation treatment planning in prostate cancer recurrences after surgery: individualized medicine or new standard in salvage treatment. Prostate. 2017;77:920-927.

73. Shakespeare TP. Effect of prostate-specific membrane antigen positron emission tomography on the decision-making of radiation oncologists. Radiat Oncol. 2015;10:233.
74. Albisinni S, Artigas C, Aoun F, et al. Clinical impact of ${ }^{68} \mathrm{Ga}$-prostate-specific membrane antigen (PSMA) positron emission tomography/computed tomography $(\mathrm{PET} / \mathrm{CT})$ in patients with prostate cancer with rising prostate-specific antigen after treatment with curative intent: preliminary analysis of a multidisciplinary approach. BJU Int. 2017;120:197-203.

75. van Leeuwen PJ, Stricker P, Hruby G, et al. ${ }^{68}$ Ga-PSMA has a high detection rate of prostate cancer recurrence outside the prostatic fossa in patients being considered for salvage radiation treatment. BJU Int. 2016;117:732-739.

76. Schiller K, Sauter K, Dewes S, et al. Patterns of failure after radical prostatectomy in prostate cancer: implications for radiation therapy planning after ${ }^{68}$ Ga-PSMA-PET imaging. Eur J Nucl Med Mol Imaging. 2017;44:16561662.

77. Calais J, Czernin J, Cao M, et al. ${ }^{68} \mathrm{Ga}$-PSMA PET/CT mapping of prostate cancer biochemical recurrence after radical prostatectomy in 270 patients with PSA level of less than $1.0 \mathrm{ng} / \mathrm{mL}$ : impact on salvage radiotherapy planning. J Nucl Med. 2018;59:230-237.

78. Roach PJ, Francis R, Emmett L, et al. The impact of ${ }^{68} \mathrm{Ga}$-PSMA PET/CT on management intent in prostate cancer: results of an Australian prospective multicenter study. J Nucl Med. 2018;59:82-88.

79. Prostate cancer: version 2.2017. National Comprehensive Cancer Network website. https://www.nccn.org/professionals/physician_gls/pdf/prostate.pdf. Published February 21, 2017. Accessed January 18, 2018.

80. Tosoian JJ, Gorin MA, Ross AE, Pienta KJ, Tran PT, Schaeffer EM. Oligometastatic prostate cancer: definitions, clinical outcomes, and treatment considerations. Nat Rev Urol. 2017;14:15-25.

81. Ost P, Reynders D, Decaestecker K, et al. Surveillance or metastasis-directed therapy for oligometastatic prostate cancer recurrence: a prospective, randomized, multicenter phase II trial. J Clin Oncol. 2018;36:446-453.

82. Akin-Akintayo OO, Jani AB, Odewole $\mathrm{O}$, et al. Change in salvage radiotherapy management based on guidance with FACBC (fluciclovine) PET/CT in postprostatectomy recurrent prostate cancer. Clin Nucl Med. 2017;42: e22-e28.

83. Garcia JR, Jorcano S, Soler M, et al. ${ }^{11} \mathrm{C}$-choline PET/CT in the primary diagnosis of prostate cancer: impact on treatment planning. $Q \mathrm{~J} \mathrm{Nucl} \mathrm{Med} \mathrm{Mol}$ Imaging. May 21, 2014 [Epub ahead of print].

84. Alongi F, Fersino S, Giaj Levra N, et al. Impact of ${ }^{18} \mathrm{~F}$-choline PET/CT in the decision-making strategy of treatment volumes in definitive prostate cancer volumetric modulated radiation therapy. Clin Nucl Med. 2015;40: e496-500. 